\title{
FUNCTIONAL CHANGES IN HEALTH INDICATORS OF STUDENTS OF HIGHER EDUCATION INSTITUTIONS \\ IN THE CONTEXT OF MUTUAL TRAINING
}

\section{Dukh Tetiana ${ }^{1}$ Svyshch Yaroslav ${ }^{2}$}

\section{DOI: https://doi.org/10.30525/978-9934-571-89-3_72}

The intensification of the learning process, the use of new teaching technologies, leads to a significant increase in the number of students who are unable to fully adapt to the load (Trout, Lambert, at all 2017). In recent years, the level of individual health of students has deteriorated significantly. There are such adverse trends in the physical development of students as asthenia, decreased chest circumference, decreased lung capacity and muscle strength. In general, only $17 \%$ of students have a satisfactory functional body state (Dukh, Lemeshko, 2016). The existing curriculum within the "Physical Education" course is currently unable to solve its most important task - improve the health of students. Therefore, every educational institution, in addition to solving pedagogical tasks, should contribute to the improvement of health and harmonious development of the individual. The outlined issues point to the need of finding new approaches to improving the educational process in physical education.

The results of the orthostatic test characterize the level of adaptation of the circulatory system and heart performance. The assessment has been carried out as follows: the heart rate up to $12 \mathrm{bpm}$ - normal response, indicating to a favorable ratio between the sympathetic and parasympathetic parts of the autonomic nervous system; the heart rate difference by more than $12 \mathrm{bpm}$ - the response is satisfactory, indicating sympathicotonia; the difference greater than $20 \mathrm{bpm}$ - indicated an overload in the heart performance and a weak level of adaptation of the circulatory system.

We have applied the Stange and Hench tests to evaluate the functional state of the cardiovascular and respiratory systems. These techniques can reveal the stability of the human body to combined hypoxia, which reflects the general state of the oxygen supplying systems of the body when breath-holding against the background of a deep breath (Stange) and against a deep exhalation (Hench test). Their results were used to determine the oxygen supply of the body and to assess the overall level of human fitness.

Stange test. The testee took a deep breath and breathed out, then took a breath again (about $80 \%$ of the maximum), closed his/her mouth and press his/her nose with the fingers, holding the breath. An excellent indicator for young and healthy people is at least 50 seconds. Hench test. Not less than $40 \mathrm{~s}$ is considered an excellent indicator for young and healthy people. The Skibinsky index allows us to assess the functional

\footnotetext{
${ }^{1}$ Lviv State University of Physical Culture, Ukraine

${ }^{2}$ Lviv State University of Physical Culture, Ukraine
} 
state of the respiratory and cardiovascular systems. The results have been evaluated on a scale: the index less than 5 - very bad, 5-9 - bad, 10-30 - satisfactory, 30-60 good, more than 60 - very good.

We used the Ruffier test to evaluate the functional state of the cardiovascular system. It consisted in the fact that the student's took 30 sits to stands in 45 seconds. The pulse was measured after a five-minute rest lying 15 seconds before the load (P1), at the beginning of the first (P2) and the second (P3) minutes of recovery. Its value has been evaluated according to the gradation: 3 - high level; 4-5 - above average; 6-10 - average; 11-13 - lower than average; more than 14 - low.

Adaptation potential of the cardiovascular system was calculated according to the R.M. Baevsky method. A certain range of oscillations in the number of points corresponds to each of the four levels of the body adaptation: satisfactory adaptation - $<2.1$ point; intensive adaptation mechanism - 2.11-3.2 points; unsatisfactory adaptation $-3.21-4.3$ points; adaptation failure -4.31 or more points. The experiment provided for the introduction of learning and teaching cards for the mutual learning of physical exercise techniques by students. Students were involved in mutual analysis of performing exercises; regular self-evaluation and mutual evaluation of personal and group achievements in the process of training was carried out. The microgroups of students were formed depending on the level of development of individual physical qualities. Classes were held in accordance with the study program for the mutual improvement of underdeveloped physical qualities (Dukh, Bodnar, Lemeshko, 2012).

The indicator for EG students has increased by $6.29 \mathrm{RU}$ in the Hench test. The average figures of this test for male corresponded to "satisfactory" estimate. The analysis of Stange test figures shows the improvement of functional capabilities of the respiratory system in EG students. Indicators improved by $10.55 \mathrm{RU}$ from "satisfactory" to "good" grade $(\mathrm{p}<0.001)$. A slight increase in reserve capacities has also taken place for male students in the CG, but no statistically significant changes have been confirmed ( $p>0.05)$. As a result of the research of Skibinsky test, a probabilistic improvement in the performance of the EG students $(p<0.001)$ has been found. The results corresponded to the satisfactory level of the respiratory system functionality. We have analyzed the level of functioning of the cardiovascular system by orthostatic test and by the Ruffier index. Analyzing the results of the Ruffie test figures in the EG, and between the EG and $\mathrm{CG}$ after the experiment, probable changes have been established $(\mathrm{p}<0.001)$. The average figures of this index in the students correspond to a satisfactory level of endurance of the cardiovascular system. There have been no statistically significant changes found in the CG students (p>0.05) (Table 1).

At the beginning of the experiment the unsatisfactory level of endurance of the cardiovascular system has been established in $19.4 \%$ of students in the EG. After the implementation of the mutual training program, there have been no student with an unsatisfactory grade of the Ruffier index. The results of the orthostatic test of the EG students at the beginning of the experiment in $9.7 \%$ of cases showed a satisfactory response of the circulatory system. At the end of the experiment, no individuals with 
satisfactory reactions have been found. At the beginning of the experiment in $15.6 \%$ of the CG students, the blood circulation system figures corresponded to satisfactory result, and at the end $-9.4 \%$. Indicative programs for the development of physical qualities built on the basis of mutual training had a positive influence on functioning of the cardiovascular system.

Table 1

Functional changes in health indicators of students

\begin{tabular}{|c|c|c|c|c|c|}
\hline Indexes & Groups & $\begin{array}{c}\mathrm{M} \pm \mathrm{SD} \\
\text { Before } \\
\text { experiment }\end{array}$ & $\begin{array}{c}\mathrm{M} \pm \mathrm{SD} \\
\text { after } \\
\text { experiment }\end{array}$ & $\mathrm{p}$ & $\begin{array}{c}\mathrm{p} \\
\text { between } \\
\mathrm{CG} \mathrm{i} \\
\mathrm{EG}\end{array}$ \\
\hline \multirow{2}{*}{ Hencha test } & $\mathrm{CG}$ & $32.72 \pm 3.82$ & $34.72 \pm 5.57$ & $>0.05$ & \multirow{2}{*}{$<0.001$} \\
\hline & EG & $31.61 \pm 4.84$ & $37.90 \pm 2.74$ & $<0.001$ & \\
\hline \multirow{2}{*}{ Stange test } & CG & $49.44 \pm 60.77$ & $51.22 \pm 9.39$ & $>0.05$ & \multirow{2}{*}{$<0.001$} \\
\hline & EG & $48.03 \pm 8.65$ & $58.58 \pm 4.45$ & $<0.001$ & \\
\hline \multirow{2}{*}{ Skibinsky index } & $\mathrm{CG}$ & $22.96 \pm 4.58$ & $24.75 \pm 5.37$ & $>0.05$ & \multirow{2}{*}{$<0.001$} \\
\hline & EG & $22.98 \pm 5.80$ & $32.57 \pm 3.87$ & $<0.001$ & \\
\hline \multirow{2}{*}{ Orthostatic test } & $\mathrm{CG}$ & $7.19 \pm 3.95$ & $7.13 \pm 3.59$ & $>0.05$ & \multirow{2}{*}{$<0.01$} \\
\hline & EG & $7.10 \pm 3.72$ & $4.87 \pm 1.75$ & $<0.01$ & \\
\hline \multirow{2}{*}{ Baevsky index } & CG & $1.84 \pm 0.26$ & $1.79 \pm 0.21$ & $<0.001$ & \multirow{2}{*}{$<0.001$} \\
\hline & EG & $1.86 \pm 0.22$ & $1.73 \pm 0.15$ & $<0.001$ & \\
\hline \multirow{2}{*}{ Ruffier index } & $\mathrm{CG}$ & $8.68 \pm 2.07$ & $8.33 \pm 1.93$ & $\geq 0.05$ & \multirow{2}{*}{$<0.001$} \\
\hline & EG & $8.58 \pm 2.07$ & $6.43 \pm 1.42$ & $<0001$ & \\
\hline
\end{tabular}

Summing up, it should be emphasized that the program of mutual training of students, developed by us, influenced to the greatest extent on functioning of the respiratory and cardiovascular system indicators, which is reflected in the likely differences between EG and CG. In the course of the experiment, probable changes $(\mathrm{p}<0.001)$ in the figures of Ruffier, Hench, Stange tests and the Skibinsky index have been found in the EG students. The number of students with the exertion of the adaptation mechanisms of the cardiovascular system after the experiment decreased by $22.5 \%(\mathrm{p}<0.01)$. The growth of the rates of the Ruffier index for EG students makes $2.15 \mathrm{RU}$.

\section{References:}

1. Alexandra L. Trout, Matthew C. Lambert, Michael H. Epstein \& Marybell Avery. Health Literacy of Students with and without Individualized Education Programs: A Brief Report: 2017; p. 35-45. URL: https://doi.org/10.1080/09362835.2017.1283630

2. Dukh T.I., Lemeshko V.Y. (2016). Characteristic functional preparation for students of higher educational institutions. Physical Culture, Sport and Health of the Nation. Collection of scientific papers, 2 (21). p. 36-42.

3. Gaetano Altavilla, Pio Alfredo di Tore, Lorenzo Riela, Tiziana D'isanto. (2017). Anthropometric, physiological and performance aspects that differentiate male athletes from 
females and practical consequences. Journal of Physical Education and Sport (JPES), 17(5), Art 226, pp. 2183-2187, doi: 10.7752/jpes.2017.s5226

4. Dukh T.I., Bodnar I.R., Lemeshko V.Y. (2012). Organization and method of mutual learning of students in physical education: educational and methodical manual, $168 \mathrm{p}$. 